\title{
Charpy Impact Toughness of Conventional and Advanced Composite Laminates for Aircraft Construction
}

\author{
José Ricardo Tarpani*, Omar Maluf*, Maria Cristina Adami Gatti* \\ Department of Materials, Aeronautics and Automotive Engineering, \\ Engineering School of São Carlos, University of São Paulo (SMM-EESC-USP) \\ Av. Trabalhador São-Carlense 400, 13566-590 São Carlos - SP, Brazil
}

Received: January 19, 2009; Revised: May 11, 2009

\begin{abstract}
A weight-based analysis was made of the translaminar Charpy impact toughness performance of conventional and advanced composite materials for aircraft fabrication. The materials were carbon-epoxy (C-Ep) and hybrid fiber-metal TiGr (Titanium-Graphite) laminates. $5 \mathrm{~mm}$-thick three-point bend specimens were tested over a temperature range of -70 to $180^{\circ} \mathrm{C}$ to reproduce typical in-service conditions of supersonic jetliners. The energies required for the processes of damage initiation $\left(\mathrm{E}_{\mathrm{i}}\right)$, damage propagation $\left(\mathrm{E}_{\mathrm{p}}\right)$, and whole fracture $\left(\mathrm{E}_{\mathrm{t}}=\mathrm{E}_{\mathrm{i}}+\mathrm{E}_{\mathrm{p}}\right)$, were evaluated at two loading rates, namely, 2.25 and $5.52 \mathrm{~m} / \mathrm{s}$ in an instrumented Charpy impact testing machine. C-Ep laminates with unidirectional fiber tapes arranged in cross-ply architecture consistently showed the best performance in terms of damage initiation toughness, whereas the hybrid fiber-metal laminate TiGr excelled in terms of propagation toughness. On the other hand, the overall performance of bi-directional fabric C-Ep laminates was very disappointing. The impact behavior of composite laminates was substantiated by a qualitative analysis of topographic aspects of fracture surfaces.
\end{abstract}

Keywords: Charpy impact testing, composite laminates, dynamic translaminar fracture, impact toughness

\section{Objective}

This work aimed at evaluating and comparing the specific (i.e., density-based) translaminar impact toughness of conventional and advanced aeronautical grade composite laminates over a wide range of temperatures.

\section{Introduction}

New technologies require structural materials with properties not usually presented by conventional metallic alloys, especially in the aeronautical industry, where high specific properties (properties/ density ratio) are at a premium. High structural efficiency leads to pay-load maximization, fuel saving, and extended fleet autonomy, among other advantages ${ }^{1}$.

Composite materials undoubtedly offer the best response to this demand; hence, increasing efforts are focusing on their development.

Traditional solid carbon-epoxy (C-Ep) laminates, in which continuous carbon fibers strengthen brittle or toughened epoxy matrices, still meet the basic design requisites for subsonic aircraft construction.

However, in commercial supersonic aircrafts (e.g., High Speed Civil Transport Project ${ }^{2}$ ), the fuselage is expected to withstand inflight temperatures as low as $-70{ }^{\circ} \mathrm{C}$ and as high as $180^{\circ} \mathrm{C}$, thus precluding the use of $\mathrm{C}$-Ep laminates and traditional aluminum alloys.

To overcome this drawback, the Boeing Co. and the National Aeronautics and Space Administration (NASA) developed the hybrid fiber-metal laminate (FML) $\mathrm{TiGr}^{3-6}$, which is composed of titanium alloy (Ti) sheets interspersed with a thermoplastic polymer matrix, PEEK (polyetheretherketone), reinforced with continuous Graphite fibers. FML materials typically meet the requisites of high stiffness, high mechanical resistance (especially to fatigue crack growth), high static fracture toughness, good capacity for absorbing transverse impact energies (transthickness impact), and high flame and corrosion resistances. These characteristics are highly desirable in the modern aeronautical industry ${ }^{7,8}$. However, the translaminar impact toughness of FMLs in the presence of notch-like defects has yet to be determined.

Several studies ${ }^{9-11}$ have been conducted in the last decade to characterize the dynamic properties of traditional structural composite laminates, especially those of the C-Ep system, using instrumented Charpy testing. For instance, Zanetti \& Tarpani ${ }^{9}$ recently carried out an experimental program to evaluate the dynamic Charpy toughness of four types of C-Ep laminates manufactured by Embraer S/A. Their results, obtained under impact velocities ranging from 1 to $5.5 \mathrm{~m} / \mathrm{s}$, are reproduced in the present study as a baseline for the Charpy impact performance of hybrid laminate TiGr. Actually, to the best of the authors' knowledge, this study is a pioneer initiative to characterize the dynamic translaminar fracture of FMLs.

Interestingly, impact loading rates provided by robust Charpy testing machines exactly match the vertical speeds of landing aircrafts (from operational to emergency conditions ${ }^{12}$ ), as well as the so-called tail-strike event, in which the aircraft tail collides with the track, culminating, in the most severe cases, in the loss of the aircraft ${ }^{13,14}$.

According to Fernández-Cantelli et al. ${ }^{10}$, widely employed standard methodologies to characterize the dynamic fracture of monolithic metals and their alloys seem to be perfectly applicable to composite materials. This means that the uncertainties generated by the dynamic test on monolithic materials would also be inherent to composites.

In the present work, translaminar Charpy impact toughness of aeronautical grade FML-TiGr and conventional C-Ep laminates are compared in terms of damage initiation $\left(\mathrm{E}_{\mathrm{i}}\right)$ and damage propagation $\left(E_{p}\right)$ energies, where $E_{i}+E_{p}$ represent the total energy $\left(E_{t}\right)$ spent in the global dynamic fracture process of the materials. 


\section{Materials and Test Specimens}

\subsection{Hybrid fiber-metal laminate (TiGr)}

$5 \mathrm{~mm}$-thick TiGr hybrid laminate was produced on a laboratory scale at the University of Liverpool-UK. TiGr consists of three $0.85 \mathrm{~mm}$-thick sheets of commercial pure titanium grade interspersed with two $1.10 \mathrm{~mm}$-thick PEEK/Gr laminates (ICI APC-2 ${ }^{\mathrm{TM}}$ ). Each PEEK/Gr laminate is composed of seven 0.14 mm-thick unidirectional tapes, with graphite fibers (Hercules AS4 ${ }^{\mathrm{TM}}$ ) occupying a volume fraction $\left(\mathrm{V}_{\mathrm{f}}\right)$ of $60 \%$ of the polymer matrix composite. According to the well-established nomenclature for FMLs, TiGr laminate obeys the arrangement $3 / 2\left(0^{\circ}\right)_{7}$.

The laminate was consolidated by hot compression in a closed metal mold, followed by controlled cooling to room temperature. PEEK impregnated graphite fibers and titanium sheets were disposed only in one direction $\left(0^{\circ}\right)$, so that the Charpy notch was machined perpendicularly to the direction of maximum mechanical resistance of the laminate. i.e., (L)ongitudinal-(T)ransverse specimen orientation. Figure 1 shows the final microstructure of TiGr laminate after a thermal stress relief cycle applied after the hot consolidation process.

The glass transition temperature $\left(\mathrm{T}_{\mathrm{g}}\right)$ of PEEK/Gr composite, which was determined by dynamic-mechanical tests and differential scanning calorimetry, ranged from 160 to $185^{\circ} \mathrm{C}^{[15]}$.

A computer image analysis of TiGr laminate indicated the following volume fractions in the hybrid material:

- PEEK polymer $=20 \%$

- Graphite fibers $=25 \%$

- Ti-alloy $=55 \%$

\subsection{Carbon-epoxy laminates (C-Ep)}

Four types of autoclave-cured vacuum bag prepreg C-Ep laminates were supplied by Embraer S/A. In two laminate series, unidirectional carbon fiber tapes (TP-60\% $\mathrm{V}_{\mathrm{f}}$ of fibers) were arranged according to the angle-ply $[0 / 90]_{7 \mathrm{~S}}$ lay-up, whereas bidirectional eight-harness satin (HS8) weave fabrics (FA-60\% $\mathrm{V}_{\mathrm{f}}$ of fibers) followed the $[0 / 90]_{14}$ pattern in the remaining two laminate series. The carbon fibers were impregnated with two different classes of epoxy resin:

i. standard grade cured at $120^{\circ} \mathrm{C}$ under an autoclave pressure of $420 \mathrm{kPa}$; and

ii. thermoplastic rubber-toughened grade cured at $180{ }^{\circ} \mathrm{C} / 700 \mathrm{kPa}$.

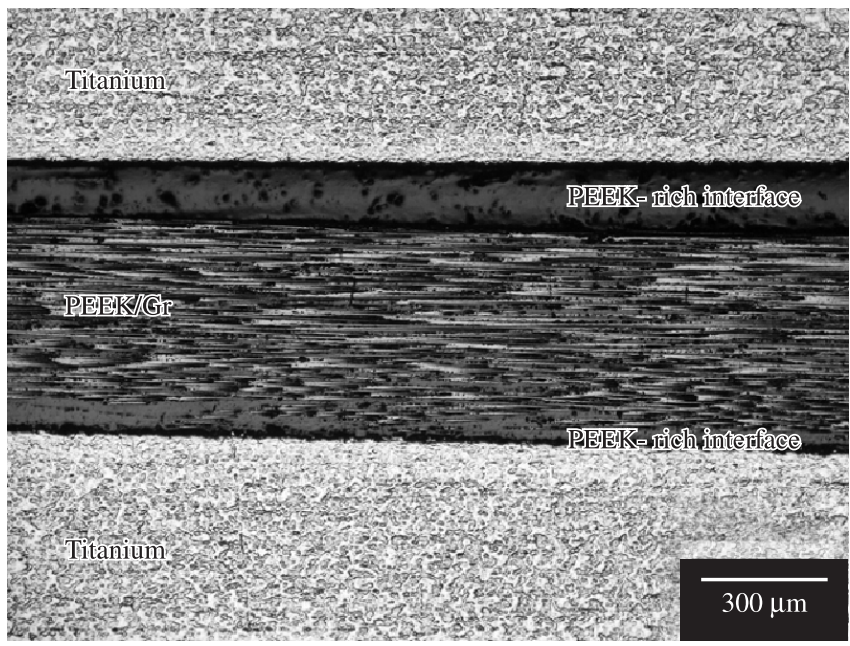

Figure 1. Longitudinal cross-section of TiGr laminate (all the constituents are identified).
As in the case of the TiGr laminate, the nominal thickness of C-Ep composites was $5 \mathrm{~mm}$. The following nomenclature was adopted for the latter materials:

- $\mathrm{TP} 120=$ Tape laminate cured at $120^{\circ} \mathrm{C}$

- $\mathrm{TP} 180=$ Tape laminate cured at $180{ }^{\circ} \mathrm{C}$

- FA120 = Fabric laminate cured at $120^{\circ} \mathrm{C}$

- FA180 = Fabric laminate cured at $180^{\circ} \mathrm{C}$

A dynamic-mechanical analysis of FA120 and FA180 laminates indicated $\mathrm{T}_{\mathrm{g}}$ temperatures of 126 and $177{ }^{\circ} \mathrm{C}^{[16]}$, respectively, confirming that the curing temperature is a good indication of the glass transition temperature of C-Ep composites.

Since all the C-Ep laminates were perfectly balanced in regard to the carbon fiber distribution in the $0^{\circ}$ and $90^{\circ}$ orientations, half the fiber content was arranged in one direction and the remainder in the other. In other words, $\mathrm{V}_{\mathrm{f}}$ is $30 \%$ in $0^{\circ}$ main direction, and therefore higher than that of hybrid laminate $\mathrm{TiGr}\left(\mathrm{V}_{\mathrm{f}}=25 \%\right)$. Thus, one can conclude that the $\mathrm{C}$-Ep laminates were somewhat more fiberstrengthened than TiGr in the longitudinal direction $\left(0^{\circ}\right)$.

\subsection{Test specimens}

Three-point-bend TiGr test specimens were waterjet cut from original sheets, while a diamond saw was employed to machine C-Ep samples. In both cases, the test specimens were finished by manual grinding to a nominal dimension of $(5 \times 10 \times 55) \mathrm{mm}^{3}$ (Figure 2). Notches were machined with a $0.5 \mathrm{~mm}$-thick diamond disk, water cooled and operating under low rotation speed. Notch positioning enforced the composite laminates to fracture in a translaminar way under pure notch opening mode I.

\section{Experimental}

Instrumented Charpy impact tests were conducted in an InstronWolpert $^{\mathrm{TM}}$ PW30 system with maximum energy capacity of $300 \mathrm{~J}$
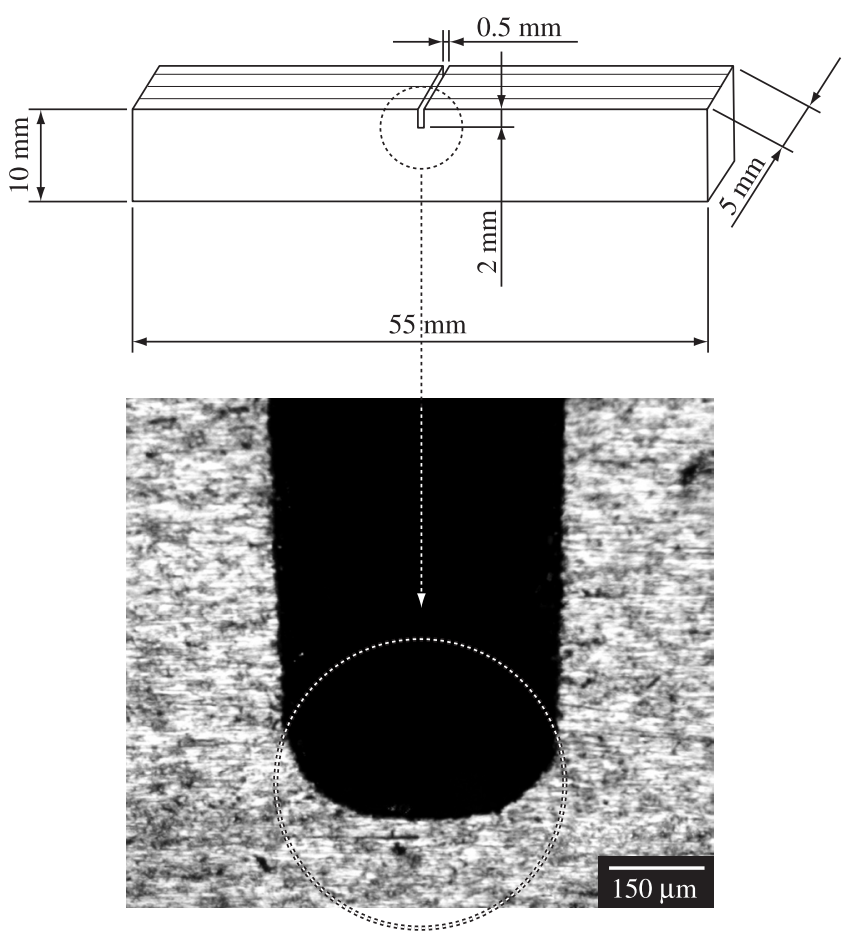

Figure 2. Three-point-bend Charpy impact test piece geometry according to the ASTM D5045 standard ${ }^{17}$ (dimensions in $\mathrm{mm}$ ). The $0.25 \mathrm{~mm}$ notch-root radius machined in a TiGr specimen illustrates the good practices adopted in this study. 


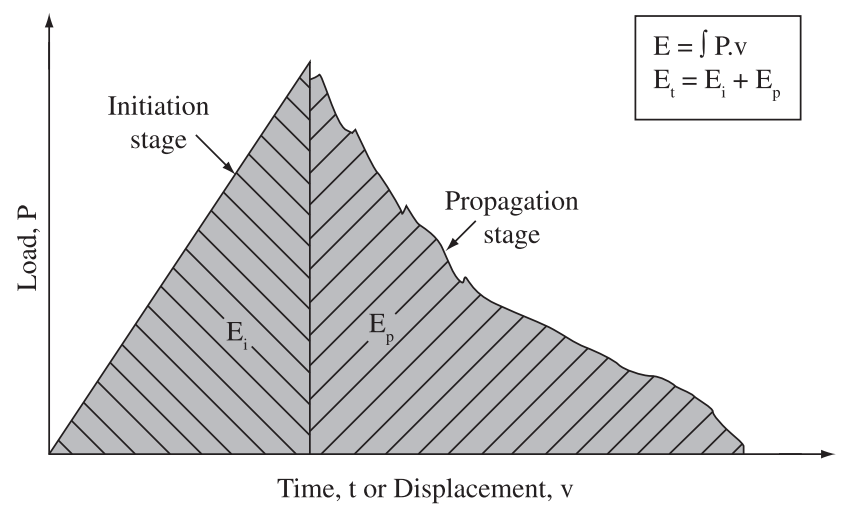

Figure 3. Typical two-stage curve obtained in instrumented Charpy impact testing 9 .

Table 1. Specific weight (dimensionless) of the tested laminates.

\begin{tabular}{lc}
\hline Laminate & Specific density (with respect to water) \\
\hline TiGr & 3.10 \\
TP120 & 1.49 \\
TP180 & 1.46 \\
FA120 & 1.47 \\
FA180 & 1.44 \\
\hline
\end{tabular}

( $5.5 \mathrm{~m} / \mathrm{s}$ hammer speed), integrated to a microcomputer operating with Instron ${ }^{\mathrm{TM}}$ and National Instruments ${ }^{\mathrm{TM}}$ software to read, treat and interpret the results in terms of net absorbed energy.

The impact hammer was instrumented with strain gauges that recorded the load signal $(\mathrm{P})$ in an oscilloscope, enabling the visualization of load $(\mathrm{P})$ variations over time $(\mathrm{t})$, while specimen load-line deflection/displacements (v) were monitored simultaneously with an optical transducer.

The P-t and P-v diagrams contain accurate information on yield and ultimate loads, and onset and arrest of unstable cracks, among other parameters. Load signal oscillations were filtered using the Matlab ${ }^{\mathrm{TM}}$ routine, via the statistical Moving Average Method.

Impact energies absorbed by the test specimens during damage initiation $\left(\mathrm{E}_{\mathrm{i}}\right)$ and damage propagation $\left(\mathrm{E}_{\mathrm{p}}\right)$ stages, respectively, were estimated by integrating P-v curves up to maximum load and after maximum load, respectively, as depicted in Figure 3.

Therefore, the total energy absorbed during the entire fracture process $\left(\mathrm{E}_{\mathrm{t}}\right)$, comprising $\mathrm{E}_{\mathrm{i}}$ and $\mathrm{E}_{\mathrm{p}}$ values, was automatically corrected for energy losses due to specimen/anvil friction, pendulum windage and specimen's broken halves tossing.

The resulting values of net absorbed energy were then divided (i.e., normalized) by the respective specific gravity of the evaluated materials (listed in Table 1), so that specific impact toughness values were derived on a weight basis, as required for aeronautical applications.

Charpy impact tests were carried out at $-196,-70,23$ and $180^{\circ} \mathrm{C}$ for FML-TiGr, applying pendulum speeds of 2.25 and $5.52 \mathrm{~m} / \mathrm{s}$. Dynamic tests of C-Ep laminates were performed only at $-70,23$ and $100{ }^{\circ} \mathrm{C}$, under identical strain rates as those applied to TiGr.

Based on the data in item 3.1, one can conclude that the hybrid laminate TiGr was mostly tested well below its glass transition temperature, with the exception of the highest test temperature of $180^{\circ} \mathrm{C}$, which is at most slightly above $\mathrm{T}_{\mathrm{g}}$. Without exception, the data in item
3.2 show that all the C-Ep laminates were tested below their glass transition temperature, i.e., in the fully brittle fracture regime.

\section{Results and Discussion}

Figure 4 plots specific (i.e., by unit weight) $E_{t}, E_{i}$ and $E_{p}$ energies, considering various temperatures and loading rates imposed in the Charpy impact tests.

The following conclusions were drawn from the plotted data points and corresponding standard deviation bars, and are divided into distinct topics for the sake of simplification:

\subsection{General impact behavior}

\subsubsection{Total composite toughness ( $\mathrm{E}_{\mathrm{t}}$ : Figures $4 \mathrm{a}$ and $\left.4 \mathrm{~b}\right)$}

TiGr and C-Ep TP laminates are tougher than C-Ep FA materials. TiGr's high performance is ascribed to the presence of both metallic and thermoplastic polymer phases, which are intrinsically ductile and tough. Moreover, the full alignment of reinforcing graphite fibers in the main direction of applied loads $\left(0^{\circ}\right)$ improved both the strength and toughness behaviors. Figure 5 shows macro- and microscopic views of TiGr's fracture surface after impact at ambient temperature and $5.5 \mathrm{~m} / \mathrm{s}$, where fiber pullout and delamination are evidenced as toughening mechanisms. C-Ep TP laminates compete with hybrid material TiGr at -70 and $100{ }^{\circ} \mathrm{C}$, under a loading rate of $2.25 \mathrm{~m} / \mathrm{s}$, although they are outperformed by the latter laminate at the intermediate temperature of $25^{\circ} \mathrm{C}$. Previous work ${ }^{18}$ showed that at $-70{ }^{\circ} \mathrm{C}$, residual thermal stresses arising from differential dimensional variation between two consecutive plies $\left(0^{\circ}\right.$ and $90^{\circ}$, respectively) in C-Ep $\mathrm{TP}$ architectures facilitate delamination, which constitutes a powerful mechanism of energy consumption. On the other hand, at $100{ }^{\circ} \mathrm{C}$, epoxy resin softening plays a fundamental role in promoting plasticity in TP laminate, giving rise to surplus toughness in the material. At a strain rate of $5.52 \mathrm{~m} / \mathrm{s}$ and room temperature, the mechanical performance of TiGr and C-Ep TP laminates is quite similar.

Figure 4 reveals an unexpectedly large data scatter of TP laminates as compared to hybrid laminate $\mathrm{TiGr}$, since the former materials were manufactured on an industrial scale while the latter was produced in the laboratory.

C-Ep TP laminates are much tougher than FA materials, and Figure 6 clearly reveals (see arrows) the uneven aspects of the fracture surface of a TP laminate (thus denoting higher levels of absorbed energy), which contrasts with the almost perfectly flat topography of the FA composite (i.e., lower energy consumption). Higher C-Ep TP impact toughness values derive also from the numerous interfaces in this laminate architecture (namely, 27 ply-interfaces compared with 13 in FA arrays), rendering it much more prone to delamination toughening. This point will be revisited in this article, although it can be postulated that crossover fiber contact points in TC woven laminates may favor fiber fracture.

The nature of the epoxy matrix affected the mechanical behavior of C-Ep laminates, and this influence seems to depend on the spatial arrangement of reinforcing carbon fibers. TP laminates are highly sensitive to the epoxy resin employed, whereas the mechanical behavior of TC materials depends only slightly on the type of thermoset polymer. Paiva et $\mathrm{al}^{19}$, who performed flexural, interlaminar shear and compressive strength tests on identical TC laminates, also confirmed the superiority of thermoplastic-toughened composites over standard epoxy resin laminates. The authors attributed this behavior to the improved fiber/matrix interface provided by the rubber-toughened resin.

The results obtained here also fully agree with previous findings by Kalthoff ${ }^{20}$ in edge-on (i.e., translaminar) Charpy specimens of 


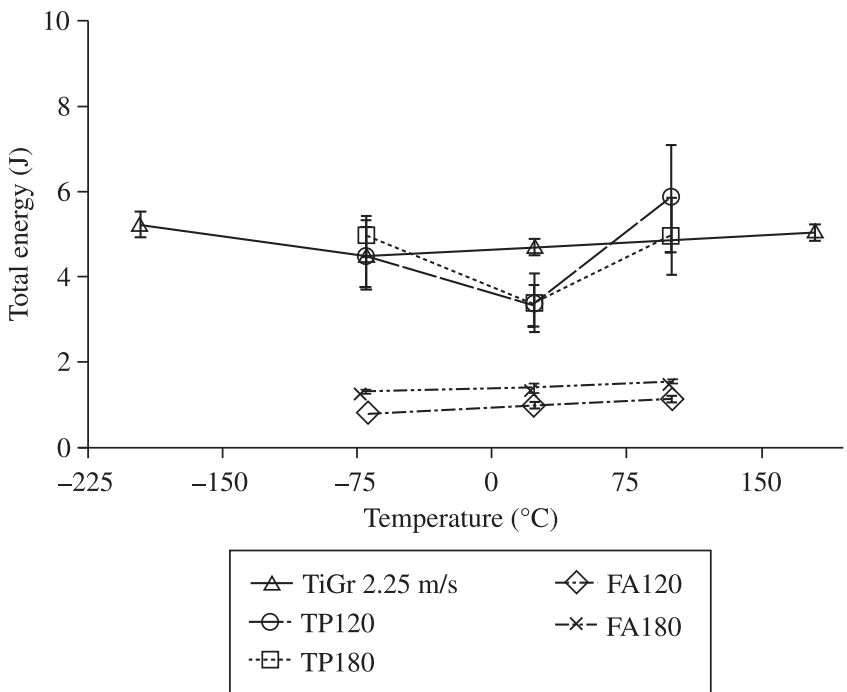

(a)

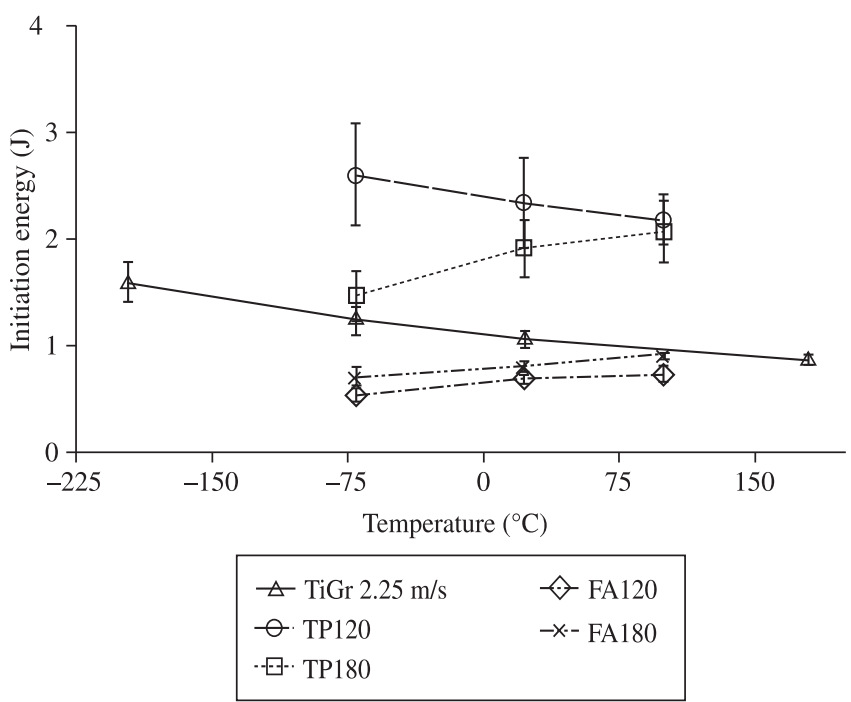

(c)

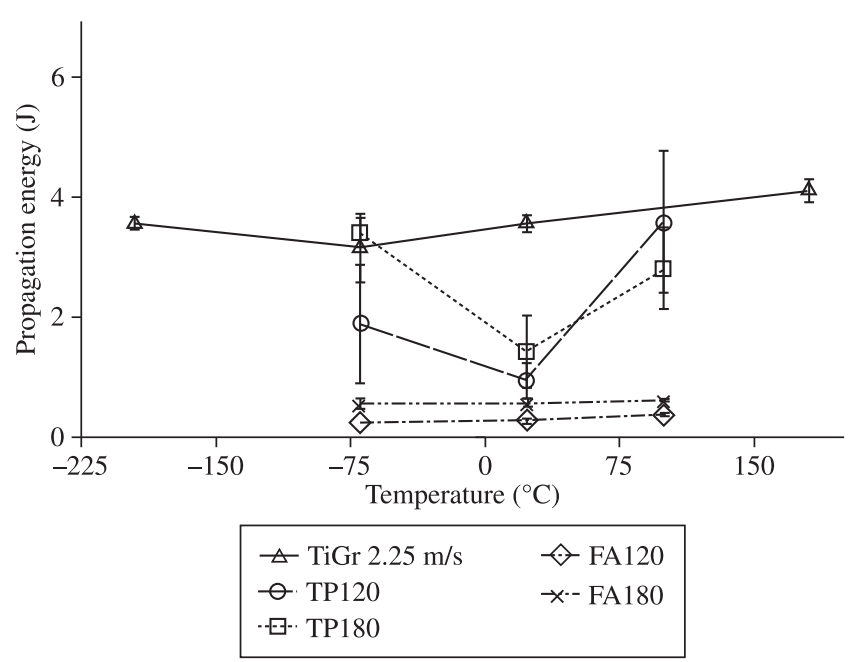

(e)

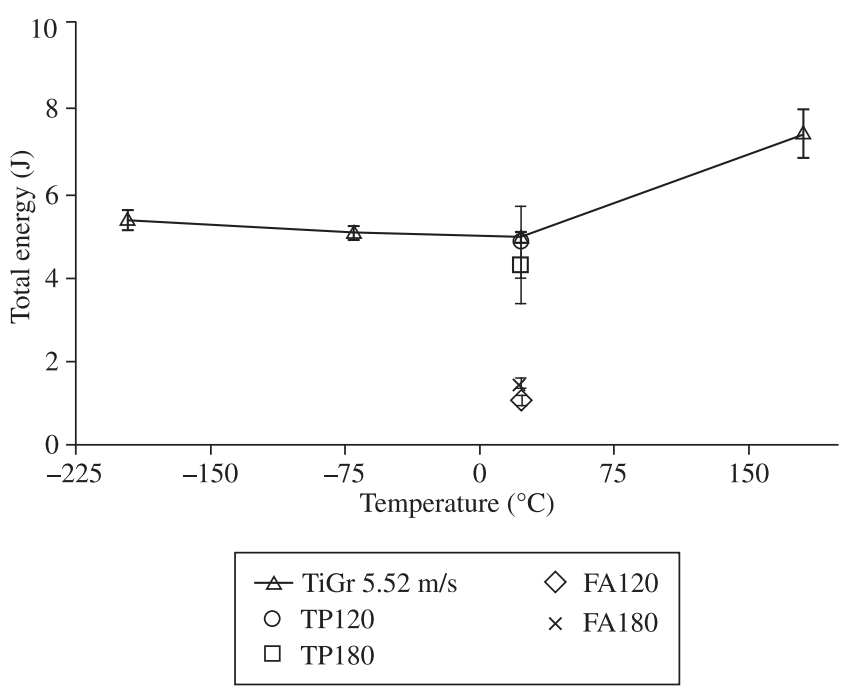

(b)

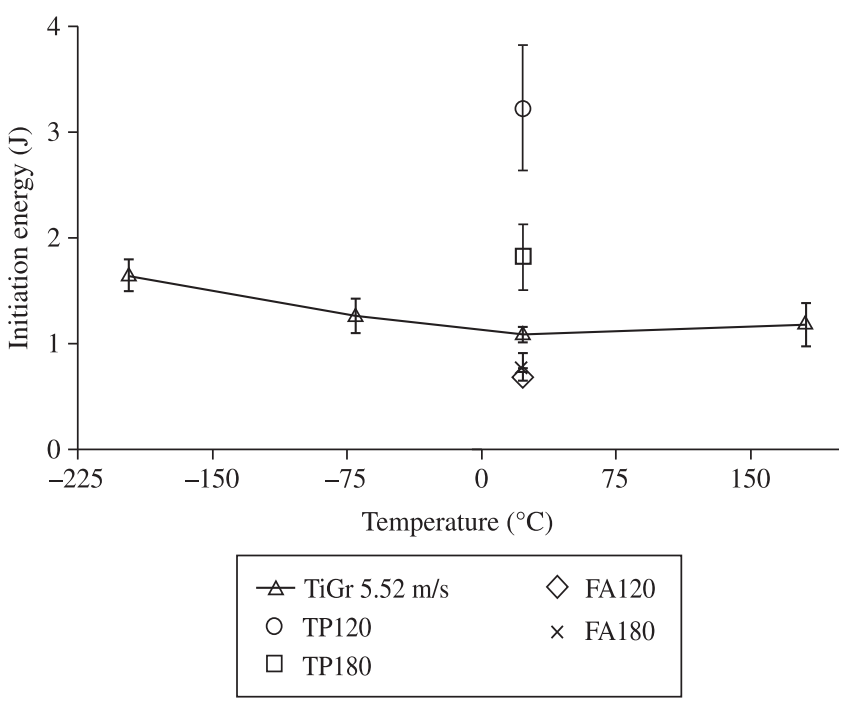

(d)

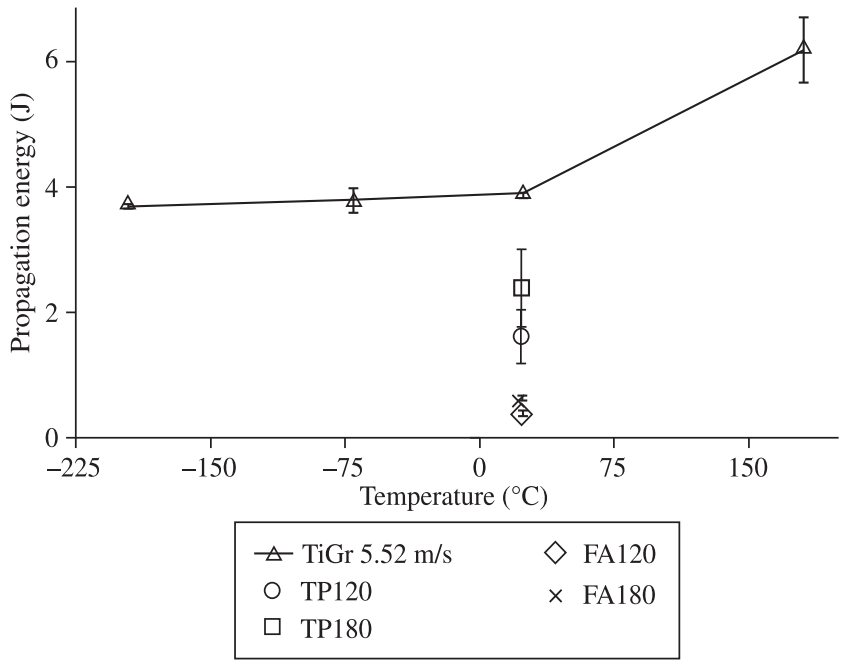

(f)

Figure 4. Specific impact toughness results for the studied laminates at different test temperatures and applied loading rates: a) and b) Total absorbed energy - $E_{i}$; c) and d) Initiation energy $-E_{i}$; e) and f) Propagation energy $-E_{p}$. Note that $E_{t}=E_{i}+E_{p}$. 

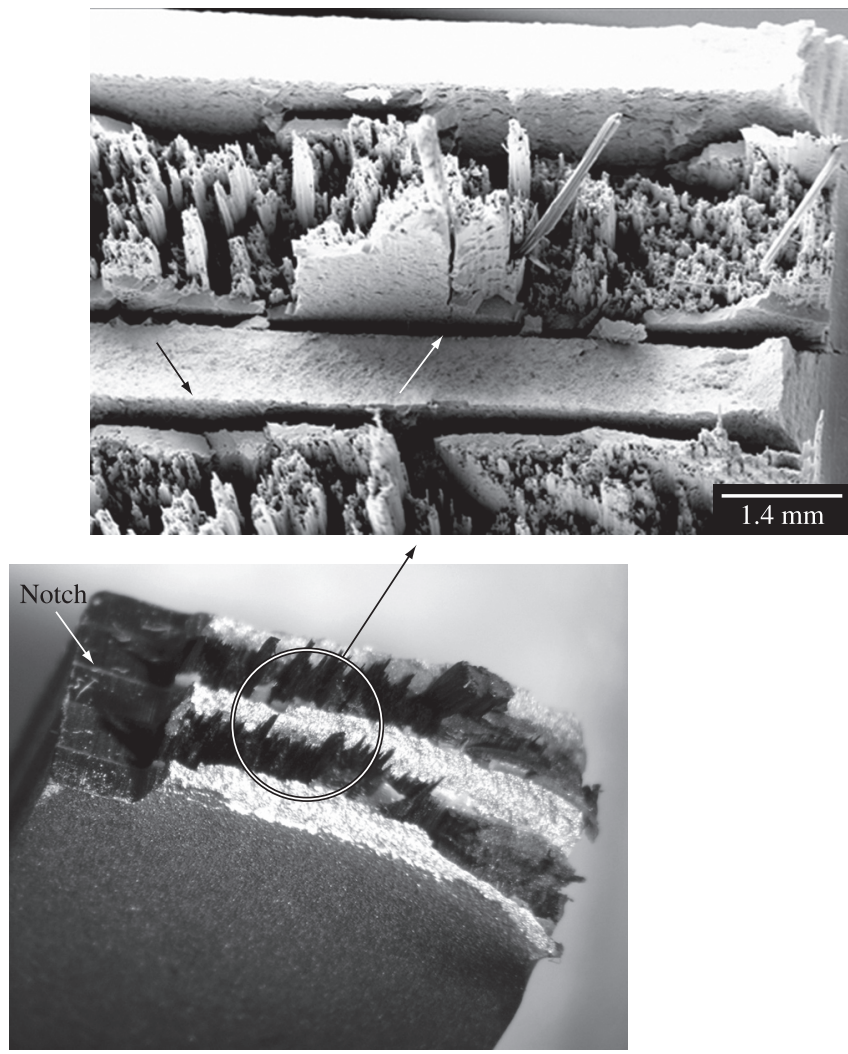

Figure 5. LT oriented FML-TiGr specimen fractured in translaminar mode I at ambient temperature and a loading rate of $5.5 \mathrm{~m} / \mathrm{s}$. The insert shows a topographic view by scanning electronic microscopy (SEM). Delaminations are arrowed.

glass-fiber/vinyl-ester composite laminates. As the author contends, "...failure takes place primarily along the ligament of the specimen, with the matrix resin broken to a large extent and extensive fracture of fibrous phase being the predominant failure mechanism".

\subsubsection{Initiation toughness ( $\mathrm{E}_{\mathrm{i}}$ : Figures $4 \mathrm{c}$ and $4 \mathrm{~d}$ )}

$E_{i}$ values of C-Ep TP laminates are invariably higher than both C-Ep FA architecture and hybrid material TiGr. As previously reported for $\mathrm{E}_{\mathrm{t}}$ values, C-Ep FA laminates are also the least tough (or the most brittle) tested materials in terms of crack/damage initiation.

The nature of the epoxy resin affects the mechanical response of the TP array significantly, but the FA architecture only slightly. As previously observed for $\mathrm{E}_{\mathrm{t}}$ values, the non-toughened epoxy resin cured at $120{ }^{\circ} \mathrm{C}$ improves TP performance in terms of $\mathrm{E}_{\mathrm{i}}$ values as well, whereas the rubber-toughened epoxy type cured at $180{ }^{\circ} \mathrm{C}$ appears more beneficial to FA laminates. This fact may, to some extent, be closely associated to the number of ply interfaces in the C-Ep laminates, inasmuch as the standard epoxy resin supposedly facilitates the delamination process in TP laminates. It is worth mentioning that initiation toughness $\left(\mathrm{E}_{\mathrm{i}}\right)$ accounts for some damage growth (including delamination) energy, since it is derived at the maximum load position of the load-displacement (P-v) diagram. It is well known that, except for completely brittle materials, initial mechanical damage actually begins at some point before the maximum load is reached ${ }^{21}$.

\subsubsection{Propagation toughness ( $E_{p}$ : Figures $4 e$ and $\left.4 f\right)$}

TiGr damage propagation energy always far exceeds damage initiation energy (i.e., $E_{p} / E_{i}>>1$ ), while no rule has yet been found for the $\mathrm{E}_{\mathrm{p}} / \mathrm{E}_{\mathrm{i}}$ ratio of C-Ep laminates.
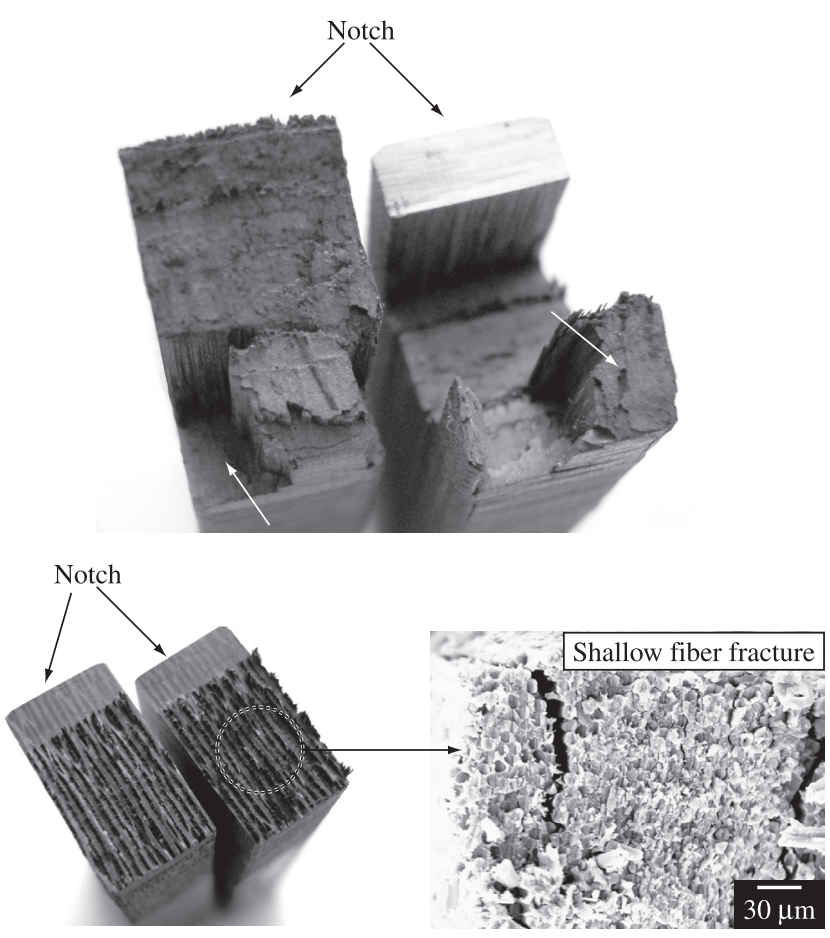

Figure 6. C-Ep fracture surfaces created under identical impact testing conditions: a) TP fiber architecture; b) FA fiber array; and c) detailed view of (b).

TiGr propagation toughness is generally higher than C-Ep composites. With regard to the TiGr material, the similarity between $\mathrm{E}_{\mathrm{p}}$ and $\mathrm{E}_{\mathrm{t}}$ values (i.e., $\mathrm{E}_{\mathrm{p}} \approx \mathrm{E}_{\mathrm{t}}>\mathrm{E}_{\mathrm{i}}$ ) and their very similar dependence on temperature and applied loading rates allows one to infer that the propagation stage controls the overall damage process of the hybrid laminate. This behavior is quite common in metals and ductile alloys, indicating that the presence of titanium and thermoplastic polymer phases, rather than delamination progress, is the main factor responsible for the impact toughness of advanced TiGr laminate.

In absolute terms, the effect of the type of epoxy matrix on the $\mathrm{E}_{\mathrm{p}}$ values of C-Ep laminates is almost insignificant for the FA array, while it is quite evident in the TP architecture.

C-Ep TP laminates perform better than FA composites. Again, this finding is very likely related to the higher potential for delamination of TP materials. In addition, Figure 7 shows the ability of this kind of composite laminate to fracture along translaminar planes oriented perpendicularly to the machined slot, thus further increasing the absorbed impact energy.

\subsection{Test temperature effect}

\subsubsection{Loading rate of $2.25 \mathrm{~m} / \mathrm{s}$}

\subsubsection{Total toughness ( $\mathrm{E}_{\mathrm{t}}:$ Figure $\left.4 \mathrm{a}\right)$}

TiGr laminate behavior is practically insensitive to thermal variations over the expected operating temperature envelope of supersonic airliners (up to $180{ }^{\circ} \mathrm{C}$ ), and C-Ep FA laminates also appear to be very little affected by this test variable within the temperature range for subsonic jetliners (up to $100{ }^{\circ} \mathrm{C}$ ).

C-EP TP laminates, however, display an atypical mechanical behavior in that the total toughness at -70 and $100{ }^{\circ} \mathrm{C}$ is higher than at the intermediate temperature of $25^{\circ} \mathrm{C}$. As mentioned previously, differential dimensional variations between two adjacent $0 / 90$ plies cooled to $-70{ }^{\circ} \mathrm{C}$ gives rise to residual thermal stresses that hasten 


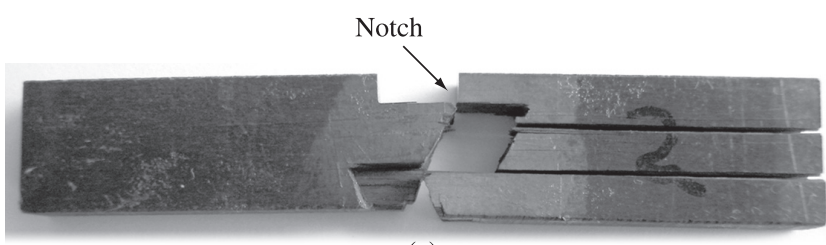

(a)

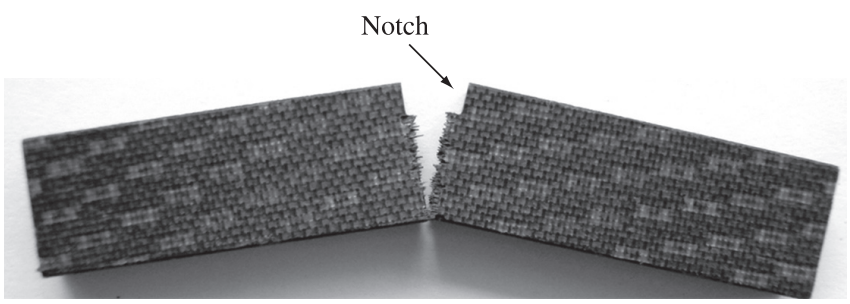

Figure 7. Impacted C-Ep laminates tested under identical conditions and exhibiting entirely different fracture patterns: a) TP120 and b) TC120.

delamination, thereby increasing the material's ability to absorb impact energy. Figure 8 confirms this assumption. On the other hand, as explained earlier, a toughening mechanism that relies on epoxy matrix softening becomes active at temperatures approaching $100^{\circ} \mathrm{C}$, especially in the standard resin cured at $120^{\circ} \mathrm{C}$, thus giving the composite laminate as a whole a certain degree of ductility.

\subsubsection{Initiation toughness $\left(\mathrm{E}_{\mathrm{i}}\right.$ : Figure $\left.4 \mathrm{c}\right)$}

Increasing the test temperature causes the absorbed energy to decrease in identical proportion in TiGr and C-Ep TP120 laminates, while other C-Ep materials display the opposite tendency. Further efforts are needed to explain these findings.

\subsubsection{Propagation toughness $\left(\mathrm{E}_{\mathrm{p}}\right.$ : Figure $\left.4 \mathrm{e}\right)$}

Unlike the initiation toughness values, there is a remarkable tendency for energy consumed in damage growth to increase with rising temperature. This indicates that, at least for the FML material, the two complementary fracture processes, i.e., damage initiation and growth, are governed by specific or particular mechanisms.

The remarkable similarity between $\mathrm{E}_{\mathrm{p}}$ (Figure $4 \mathrm{e}$ ) and $\mathrm{E}_{\mathrm{t}}$ (Figure $4 \mathrm{a}$ ) dependence on temperature and loading rate for C-Ep laminates, analogous to what was previously observed for TiGr laminate, allows one to conclude that the damage propagation stage largely controls the material's total toughness at the expense of the damage initiation phase. Therefore, the same reasoning developed earlier to explain the minimum peak attained by the total toughness parameter $\left(\mathrm{E}_{\mathrm{t}}\right)$ of C-Ep TP laminates at ambient temperature, comparatively to the values obtained at -70 and $100{ }^{\circ} \mathrm{C}$, can explain the behavior of $\mathrm{E}_{\mathrm{p}}$ toughness.

\subsubsection{Loading rate of $5.52 \mathrm{~m} / \mathrm{s}$}

\subsubsection{Total toughness $\left(\mathrm{E}_{\mathrm{t}}\right.$ : Figure $\left.4 \mathrm{~b}\right)$}

The TiGr laminate exhibits no dependence on temperature up to $25^{\circ} \mathrm{C}$, but higher temperatures affect favorably the material's performance. This behavior is congruent with the massive presence of both metal and polymer phases in the hybrid fiber-metal laminate, to the extent that the material's ductility general benefits from increasing temperatures.

\subsubsection{Initiation toughness $\left(\mathrm{E}_{\mathrm{i}}\right.$ : Figure $\left.4 \mathrm{~d}\right)$}

Increasing temperature impairs TiGr performance up to $25^{\circ} \mathrm{C}$, but the material becomes insensitive to this test variable at higher

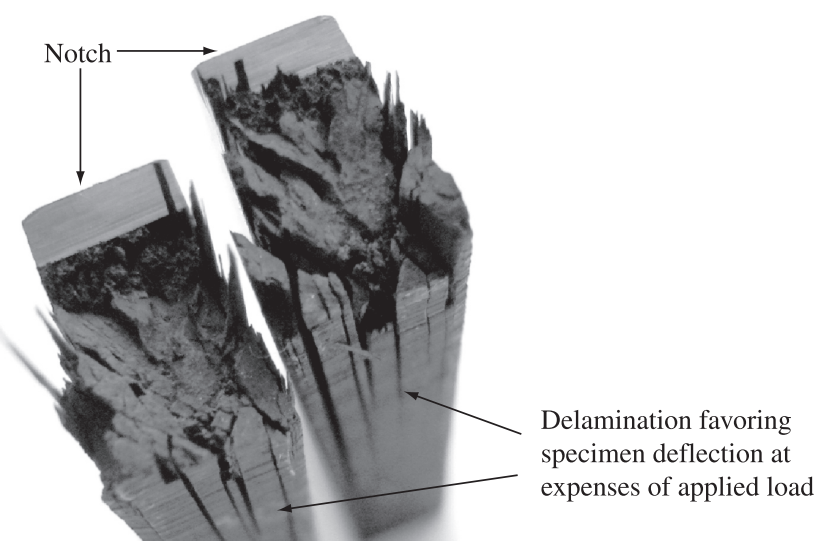

Figure 8. Test piece halves of impacted TP180 laminate tested at $-70{ }^{\circ} \mathrm{C}$, with numerous delamination planes (indicated by arrows), promoted by thermally-induced differential dimensional changes between two neighboring 0/90 plies.

temperatures. Interestingly, this behavior differs completely from that of the $\mathrm{E}_{\mathrm{p}}$ toughness, corroborating a preceding statement about the complementary nature of fracture initiation and growth processes in the hybrid fiber-metal laminate.

\subsubsection{Propagation toughness ( $E_{p}$ : Figure $\left.4 f\right)$}

TiGr laminate displays the same tendency as observed earlier for the total energy, $E_{\mathrm{t}}$ (Figure $4 \mathrm{~b}$ ), which, in turn, counteracts the initiation energy, $E_{\mathrm{i}}$ (Figure $4 \mathrm{~d}$ ). The similarity between $\mathrm{E}_{\mathrm{p}}$ and $\mathrm{E}_{\mathrm{t}}$ dependence on temperature has already been correlated to the prevalence of the damage propagation stage over the damage initiation phase in the global dynamic fracture process of this hybrid material.

For both loading rates evaluated, the $\mathrm{E}_{\mathrm{p}} / \mathrm{E}_{\mathrm{i}}$ ratio of TiGr ranges from approximately 2.5 to 5 as the temperature rises from -70 to $180{ }^{\circ} \mathrm{C}$. For C-Ep laminates, this relationship is usually lower than unity, indicating that the damage initiation stage drives the dynamic fracture process. However, as the temperature approaches $100^{\circ} \mathrm{C}$, the propagation stage begins to predominate, so that at higher temperatures the $\mathrm{E}_{\mathrm{p}} / \mathrm{E}_{\mathrm{i}}$ ratio assumes values higher than but still close to 1 .

\subsection{Loading rate effect}

\subsubsection{Total toughness ( $\mathrm{E}_{\mathrm{t}}$ : Figures $4 \mathrm{a}$ and $\left.4 \mathrm{~b}\right)$}

TiGr is sensitive to the applied loading rate at temperatures above $25^{\circ} \mathrm{C}$, when a significant increase in $\mathrm{E}_{\mathrm{t}}$ occurs due to increasing impact speed. This behavior is typical of ductile materials, whose fracture process is strain-controlled, and is consistent with the presence of metallic titanium and thermoplastic PEEK in the FML composition.

With regard to most of C-Ep laminates studied, nothing can be stated about the loading rate effect since the standard deviation ranges overlap at both impact velocities at room temperature. The only exception is the TP120 laminate, which seems to be favorably affected by higher applied strain rates.

\subsubsection{Initiation toughness $\left(\mathrm{E}_{\mathrm{i}}\right.$ : Figures $4 \mathrm{c}$ and $\left.4 \mathrm{~d}\right)$}

For the TiGr laminate, a beneficial increasing loading rate effect occurs at temperatures above $25^{\circ} \mathrm{C}$, similarly to the earlier analysis of the $\mathrm{E}_{\mathrm{t}}$ criterion (Figs.04a and 04b). 


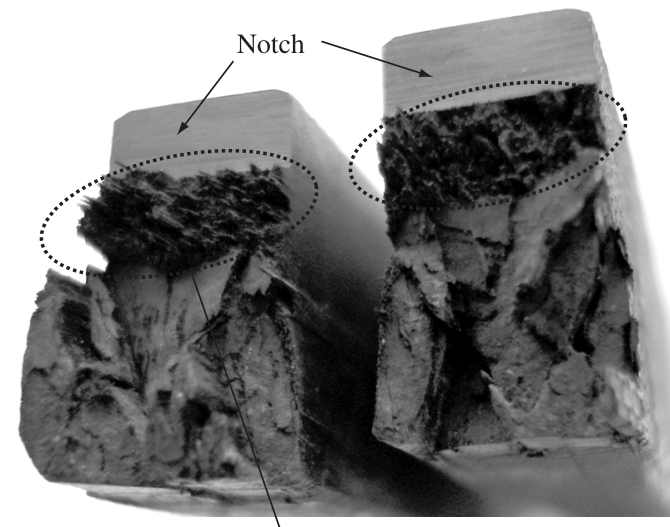

(a)

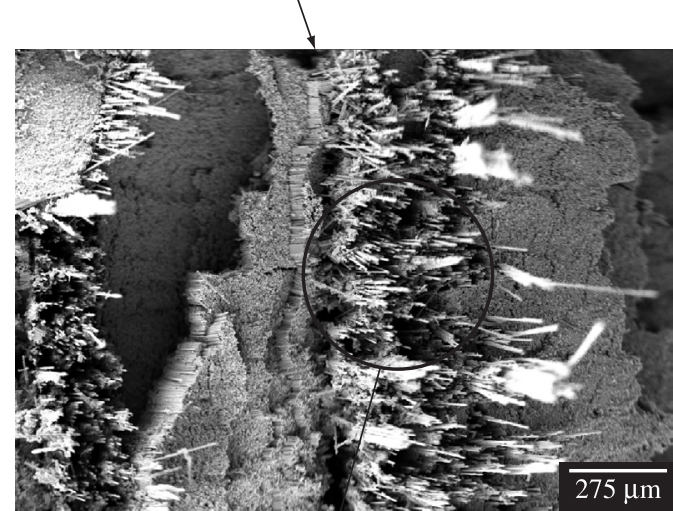

(b)

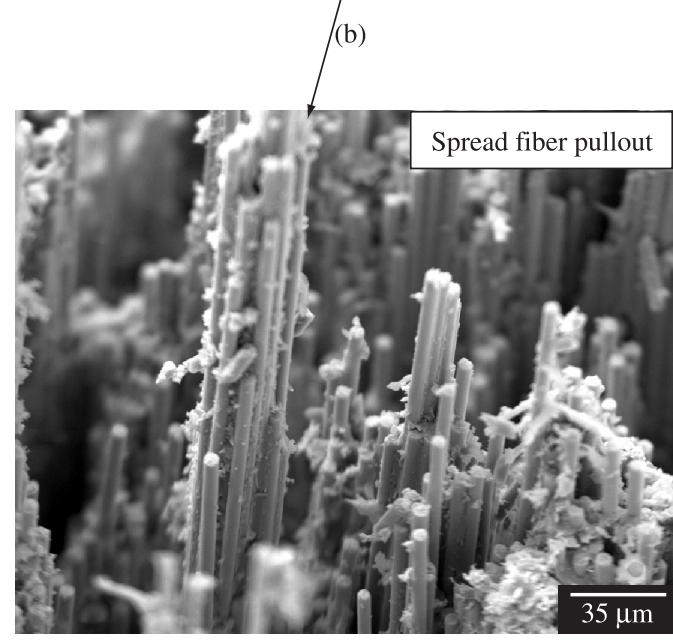

(c)

Figure 9. Fracture surface profile of impacted TP 180 laminate tested at $100{ }^{\circ} \mathrm{C}$ : a) Macroscopic view; b) SEM view; and c) SEM magnification of (b).

C-Ep TP laminates outperform FML-TiGr in terms of the initiation toughness criterion. Like the hybrid laminate at temperatures above $25^{\circ} \mathrm{C}$, the TP120 composite is also favorably affected by increasing temperature, whereas the influence of temperature on the TP180 laminate is negligible or nonexistent. Figure 9 shows fracture surface features of a C-Ep TP specimen; fiber pullout is clearly visible next to the notch root (dotted ellipse areas), confirming the high damage initiation toughness values determined experimentally for this class of composite laminate.

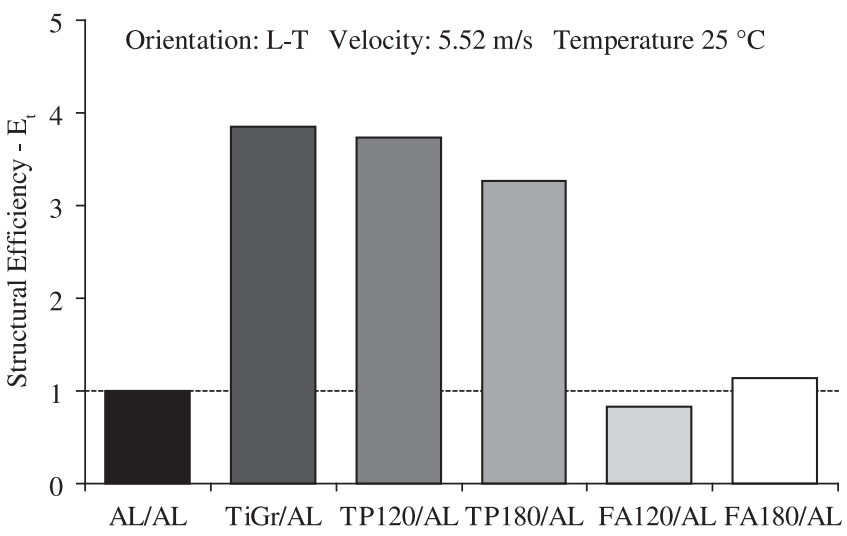

(a)

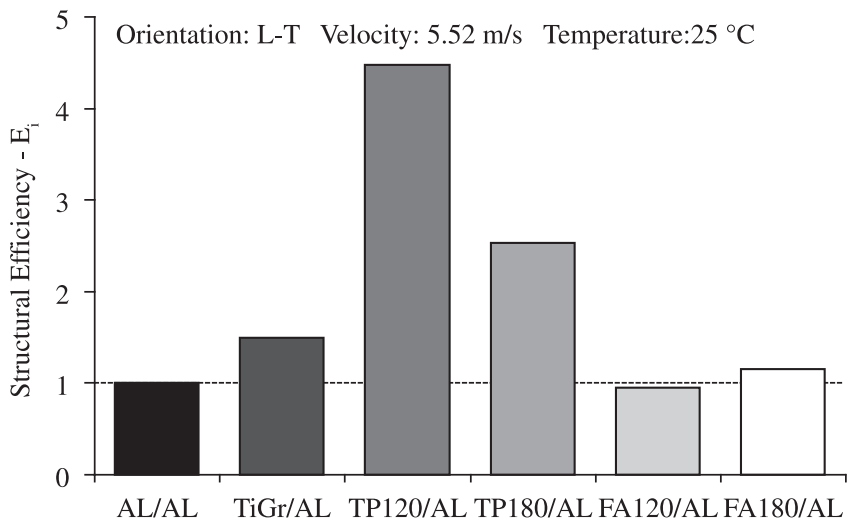

(b)

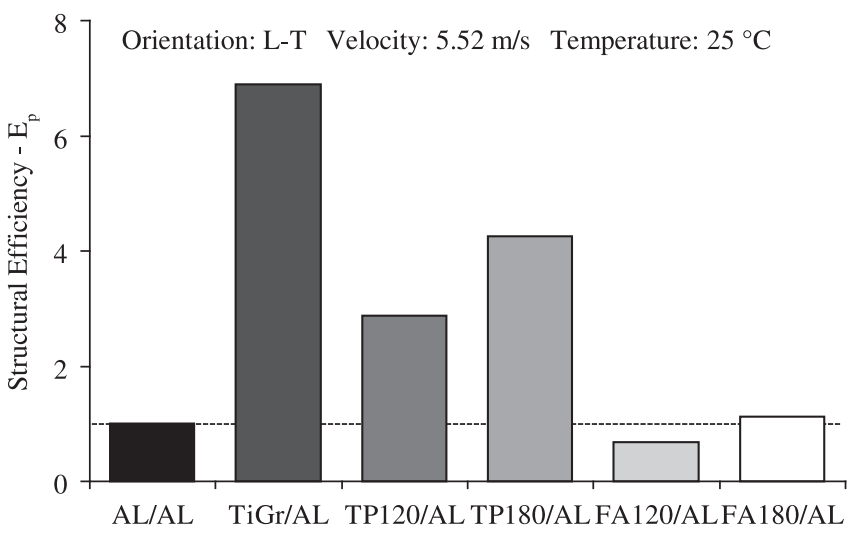

(c)

Figure 10. Structural efficiency charts normalized with respect to the impact performance of an Al-alloy (AL) at ambient temperature: a) Total fracture energy, $E_{t}$; b) Initiation fracture energy, $E_{i}$; and c) Propagation fracture energy, $\mathrm{E}_{\mathrm{p}}$.

\subsubsection{Propagation toughness $\left(\mathrm{E}_{\mathrm{p}}\right.$ : Figures $4 \mathrm{e}$ and $\left.4 \mathrm{f}\right)$}

Increasing the loading rate has a positive effect on TiGr laminate tested above ambient temperature. The same trend was also observed for the $\mathrm{E}_{\mathrm{t}}$ (Figures $4 \mathrm{a}$ and $4 \mathrm{~b}$ ) and $\mathrm{E}_{\mathrm{i}}$ (Figures $4 \mathrm{c}$ and $4 \mathrm{~d}$ ) toughness of the hybrid material. The presence of metallic titanium and thermoplastic PEEK polymer in the FML composition was already found to be responsible for this behavior. 
C-Ep TP laminates are positively affected by higher loading rates, whereas no definitive statement can be made about the influence of the strain rate on the behavior of FA composites.

\subsection{Ranking of structural efficiency}

Structural efficiency refers to the quotient between specific mechanical properties (property/density ratio) of two concurrent materials devised for a particular structural application ${ }^{1}$.

Basically, the structural efficiency index describes the weight saving (or inversely the weight penalty) obtained by replacing one material with another. For example, from a quotient A'/B' of 1.25 , where A' and B' are specific mechanical properties (e.g., fracture toughness) of metallic alloys A and B, respectively, it may be concluded that the structural component made of B-alloy is $25 \%$ heavier than the same piece manufactured from A-alloy. Conversely, the component made of A-alloy weighs only $80 \%$ (1/1.25) of that constructed of B-alloy.

Figure 10 provides comparative bar charts of the structural efficiency of materials tested for Charpy impact toughness $\left(E_{i}, E_{p}\right.$ and $\mathrm{E}_{\mathrm{t}}$ ), using as reference the dynamic performance of an aeronautical grade 7475-T7351 aluminum-alloy at ambient temperature and a loading rate of $5.52 \mathrm{~m} / \mathrm{s}$.

This type of graph better expresses and compares the results shown in Figure 4 (line plots).

In summary, the following information can be extracted from Figure 10:

i. In terms of the $\mathrm{E}_{\mathrm{t}}$ criterion (Figure 10a), hybrid laminate TiGr is the most efficient material for lightweight structures, followed closely by C-Ep TP laminates. In contrast, FA laminates are the least efficient materials, performing similarly to conventional Al-alloys;

ii. Concerning the initiation toughness $\mathrm{E}_{\mathrm{i}}(10 \mathrm{~b}), \mathrm{TP} 120$ laminate exhibits outstanding structural efficiency, whereas TiGr material is outperformed even by the TP180 laminate, thus approaching the behaviour of both the metallic alloy and C-Ep FA composite;

iii. With regard to the propagation toughness $\mathrm{E}_{\mathrm{p}}$ (Figure 10c), hybrid laminate TiGr is far superior to $\mathrm{C}$-Ep TP materials, with FA laminates again displaying the worst performance, along with Al-alloy; and

iv. More balanced $\mathrm{E}_{\mathrm{i}}$ and $\mathrm{E}_{\mathrm{p}}$ properties (where $\mathrm{E}_{\mathrm{i}}+\mathrm{E}_{\mathrm{p}}=\mathrm{E}_{\mathrm{t}}$ ) are provided by TP180 laminate.

Recalling that TiGr laminate possesses less reinforcing fibers in the main $0^{\circ}$ direction than C-Ep composites, it can be argued that the very good performance of the former material regarding both the $\mathrm{E}_{\mathrm{t}}$ and $\mathrm{E}_{\mathrm{p}}$ criteria can be further improved.

\section{Closing Remarks}

In this work, translaminar damage initiation and growth toughnesses of an advanced fiber-metal hybrid (TiGr) laminate and conventional carbon-epoxy (C-Ep) laminates were determined at two impact loading rates over a wide range of temperatures and compared on a specific (weight) basis. The following main conclusions were drawn from this study:

- Within the temperature range of -70 to $100{ }^{\circ} \mathrm{C}, \mathrm{C}$-Ep TP and TiGr laminates exhibit very similar mechanical performance in terms of total impact toughness (damage initiation + propagation stages).

- If one considers damage initiation and damage growth stages separately, the performance of C-Ep TP laminates surpasses that of TiGr in terms of the initiation criterion, while the former materials are correspondingly outperformed by the latter, and in identical proportion, in terms of the propagation criterion;

- Among the tested C-Ep laminates widely employed in primary and secondary subsonic commercial aircraft structures, unidirectional tape (TP) arranged in cross-ply array, impregnated with standard epoxy resin cured at $120^{\circ} \mathrm{C}$, displayed the best overall results. Interestingly, this is the cheapest grade of C-Ep laminate presently evaluated.

- There is a general tendency for impact toughness to increase by increasing the temperature and/or loading rate, which is compatible with the behavior of most engineered structural materials.

- C-Ep FA materials displayed the poorest translaminar Charpy impact performance when compared with concurrent laminated materials.

- The fractographic survey of impacted specimens supplied substantial evidence to support experimental results in terms of energy consumption in both damage initiation and growth phases.

- The instrumented Charpy impact test method proved successful in differentiating the dynamic translaminar fracture behavior of conventional and advanced composite laminates, indicating its potential as a powerful tool for selecting structural materials for aircraft designs that rely on impact damage resistance.

\section{Acknowledgements}

The authors acknowledge CAPES for a doctoral grant awarded to M.C.A.G. We are indebted to Embraer S/A for supplying C-Ep laminates, Prof. James Wesley Cantwell for the facilities made available for the preparation of FML-TiGr in the Laboratory of Composite Materials at the University of Liverpool (UK), to MSc. Douglas Serpa Zanetti, from the Materials Science and Engineering Program at Interunidades-USP, for sharing experimental results, and to Guilherme A. Teti, from the Aeronautical Engineering Graduate Program at SMM-EESC-USP, for his assistance with the impact experiments.

\section{References}

1. Niu MCY. Composite airframe structures. Hong Kong: Conmilit Press; 1992.

2. Aeronautical Technologies for the Twenty-First Century. High Speed Civil Transport. Washington-DC: National Academy Press; 1992.

3. Burianek DA, Giannakopoulos AE and Spearing SM. Modeling of facesheet crack growth in titanium-graphite hybrid laminates - part II: experimental results. Engineering Fracture Mechanics. 2003; 70(6):799-812.

4. Rhymer DW and Johnson WS. Fatigue damage mechanisms in advanced hybrid titanium composite laminates. International Journal of Fatigue. 2002; 24(9):995-1001.

5. Cortés P and Cantwell WJ. Interfacial fracture properties of carbon fiber reinforced PEEK/titanium fiber-metal laminates. Journal of Materials Science Letters. 2002; 21(23):1819-1823.

6. Li E and Johnson WS. An investigation into the fatigue of a hybrid titanium composite laminate. Journal of Composite Technology and Research. 1998; 20(1):3-12.

7. Vogelesang LB and Vlot A. Development of fibre-metal laminates for advanced aerospace structures. Journal of Materials Processing Technology. 2000; 103(1):1-5.

8. Vlot A, Kroon E and La Rocca G. Impact response of fiber metal laminates. Key Engineering Materials. 1998; 141-143(1):235-276.

9. Zanetti $\mathrm{D}$ and Tarpani JR. Tenacidade à fratura translaminar dinâmica de laminados compostos carbono-epóxi de grau aeronáutico [Dissertation]. São Carlos: Engineering School of São Carlos, University of São Paulo; 2005.

10. Fernández-Cantelli A, Argüeles A, Viña J, Ramulu M and Kobayashi AS. Dynamic fracture toughness measurements in composites by instrumented 
Charpy testing: influence of aging. Composite Science and Technology. 2002; 62(10-11):1315-1325.

11. Burzic $Z$. The effect of fiber orientation on impact toughness and fracture properties of carbon fiber-epoxy composite. In: Proceedings of the Charpy Centenary Conference; 2001; Poitiers.

12. Alves M, Chaves $\mathrm{C}$ and Birch RS. Impact on aircraft. In: Proceedings of the XVII Brazilian Congress of Mechanical Engineering; 2003; São Paulo. São Paulo; 2003.

13. Aviation Safety Network. Accident description: Boeing 747SR46. Available from: <http://aviation-safety.net/database/record. php?id=19850812-1>. Access in: 15/09/2007.

14. Aviation Safety Network. Accident description: Boeing 747-209B. Available from: <http://aviation-safety.net/database/record. php?id=20020525-0 $>$. Access in: 15/09/2007.

15. Gatti MCA, Silva RV and Tarpani JR. Análise térmica do laminado PEEK/ carbono submetido a diferentes rotas de processamento. Revista Matéria. 2006; 11(3):332-339.

16. Paiva JMF, Mayer S, Cândido GM and Rezende MC. Avaliação da temperatura de transição vítrea de compósitos poliméricos reparados de uso aeronáutico. Polímeros: Ciência e Tecnologia. 2006; 16(1):79-87.
17. Standard Test Methods for Plane-Strain Fracture Toughness and Strain Energy Release Rate of Plastic Materials. Designation ASTM D5045-96. Philadelphia: American Society for Testing and Materials Handbook; 2001.

18. Gatti MCA and Tarpani JR. Desempenho sob impacto Charpy de laminados compostos convencionais e avançados da indústria aeronáutica. In: Proceedings of the $62^{\text {nd }}$ International Congress of the Brazilian Association for Metallurgy and Materials; 2007; Vitória.

19. Paiva JMF, Mayer S and Rezende MC. Evaluation of mechanical properties of four different carbon/epoxy composites used in aeronautical field. Materials Research. 2005; 8(1):91-97.

20. Kalthoff JF. Characterization of the dynamic failure behaviour of a glass-fiber/vinyl-ester at different temperatures by means of instrumented Charpy impact testing. Composites Part B: Engineering. 2004; 35(68):657-663.

21. Cheresh MC and McMichael S. Instrumented impact test data interpretation. In: Kessler SL, Adams GC, Driscoll SB, Ireland DR, editors. Instrumented impact testing of plastics and composites materials. Philadelphia: American Society for Testing and Materials; 1985. p. 9-23. ASTM Special Technical Publication 936. 